\title{
How to stent the ureter after kidney transplantation in children?-A comparison of two methods of urinary drainage
}

\author{
Anuradha S. ter Haar ${ }^{1}$ (D) | Rulan S. Parekh² | Ralph W. J. Leunissen ${ }^{1}$ | \\ Joop van den Hoek ${ }^{3}$ | Armando J. Lorenzo ${ }^{4}$ | Diane Hebert ${ }^{2}$ | Mandy G. Keijzer-Veen ${ }^{5}$ | \\ Karlien Cransberg ${ }^{1}$
}

\author{
${ }^{1}$ Department of Pediatric Nephrology, \\ Erasmus MC-Sophia Children's Hospital, \\ Rotterdam, The Netherlands \\ ${ }^{2}$ Department of Pediatric Nephrology, The \\ Hospital for Sick Children, University of \\ Toronto, Toronto, Canada \\ ${ }^{3}$ Department of Pediatric Urology, Erasmus \\ MC-Sophia Children's Hospital, Rotterdam, \\ The Netherlands \\ ${ }^{4}$ Division of Urology, The Hospital for Sick \\ Children, University of Toronto, Toronto, \\ Canada \\ ${ }^{5}$ Department of Pediatric Nephrology, \\ Wilhelmina Children's Hospital, \\ University Medical Center Utrecht, Utrecht, \\ The Netherlands \\ Correspondence \\ Karlien Cransberg, Department of Pediatric \\ Nephrology, Erasmus MC-Sophia Children's \\ Hospital, Rotterdam, The Netherlands. \\ Email: k.cransberg@erasmusmc.nl
}

\begin{abstract}
Ureteral stenting after pediatric renal transplantation serves to prevent obstruction and urinary leakage, but can also cause complications. This study compares the complication rates of both methods. Data were retrospectively collected at Erasmus MC, Rotterdam, the Netherlands (splint group, $\mathrm{n}=61$ ) and Hospital for Sick Children, Toronto, Canada ( $J$ catheter group, $n=50$ ). Outcome measures included urological interventions and incidence of UTIs during the first 3 months post-transplantation. The splint was removed after a median of 9 (IQR 8-12), the JJ catheter after 42 (IQR 36-50) days. Seven (11.5\%) children in the splint group needed at least one urological re-intervention versus two in the $\mathrm{JJ}$ catheter group ( $P$-value .20). UTIs developed in 19 children (31.1\%) in the splint group and in twenty-five (50.0\%) children in the $\mathrm{JJ}$ catheter group ( $P$-value .04), with a total number of 27 vs. 57 UTIs ( $P$-value .02). Nine (33.3\%) vs. 35 (61.4\%) of these, respectively, occurred during the presence of the splint $(P$-value <.001). Children with a JJ catheter developed more UTIs than children with a splint; the latter, however, tended to require more re-interventions. Modification of either method is needed to find the best way to stent the ureter.
\end{abstract}

KEYWORDS

children, double $\mathrm{J}$ catheter, renal transplantation, splint, ureteral stent, urinary tract infections

\section{1 | INTRODUCTION}

Kidney transplantation is the preferred method to treat children with end-stage renal disease. ${ }^{1,2}$ The surgical procedure can be cumbersome, however, due to the small sizes of the iliac fossa and blood vessels, especially when transplanting an adult kidney in very young recipients. It is therefore associated with a higher surgical complication rate than in adults, especially in the case of young children. ${ }^{3-6}$ Urological complications, generally related to the ureteroneocystostomy, are

Abbreviations: ATG, antithymocyte globulin; CAKUT, congenital anomalies of the kidney and urinary tract; $\mathrm{CIC}$, clean intermittent catheterization; IQR, interquartile range; $L D$, living donor; PCN, percutaneous nephrostomy; UTIs, urinary tract infections; VUR, vesicoureteral reflux at cystourethrogram. most common, with a reported incidence of $3 \%-34 \% .^{7}$ The reported incidences of obstruction of the newly implanted transplant ureter, or leakage at the site of re-implantation into the recipient urinary bladder, vary from $2 \%$ to $14 \%{ }^{7}$

Although the introduction in the 1990s of stenting of the ureterovesical anastomosis in adults was expected to lower this complication rate, the practice of stenting itself proved a new source of complications such as UTls. ${ }^{8-10}$ Even BK viremia has been demonstrated to be associated with stenting the ureter by a J catheter. ${ }^{11,12}$ Nevertheless, in 2004 and 2013 a meta-analysis ${ }^{13}$ and a Cochrane review, ${ }^{14}$ respectively, demonstrated that routine intraoperative ureteral stenting in adults lowered the urinary leakage and obstruction rates. These results were confirmed by a prospective 
randomized clinical trial and four large retrospective studies using the double $J$ catheter stent ( $J J$ catheter) and a study using external stenting. ${ }^{8,9,15-18}$ In children, a few studies have provided arguments for and against the use of ureteral stents. Stenting was associated with significantly fewer ureteric obstruction and urological complications in two studies, ${ }^{19,20}$ whereas two other studies found no difference, but reported adverse events such as stent migration and UTIs. ${ }^{11,21}$

The most frequently used ureteral stent, the $\mathrm{J}$ catheter, is placed from the bladder through the newly implanted ureter into the renal pelvis and remains in situ for up to 6-8 weeks, and is then removed by cystoscopy. An alternative method is external stenting by a pyelovesicocutaneous catheter (splint), where the catheter, with the tip located in the pelvis, traverses the ureter and bladder and opens through the abdominal wall (Figure 1). It usually remains in place between 4 and 10 days, and is easily pulled out.

External stenting with a splint has a special advantage: It allows monitoring of the urine from the transplanted kidney separately from that of the native kidneys, which can be especially important in case of focal segmental glomerulosclerosis or polyuric native kidneys.

To determine the optimal method to stent the ureter, we compared the complication rates and outcomes of the first 3 months after pediatric renal transplantation of external stenting by a splint versus the "classic" JJ catheter method in two centers of pediatric transplantation, each with expertise in one of the methods.

\section{2 | PATIENTS AND METHODS}

\section{1 | Study design and population}

This retrospective cohort study was conducted at two academic centers for pediatric kidney transplantation, the Erasmus MC-Sophia Children's Hospital (Erasmus MC, Rotterdam, the Netherlands) and the Hospital for Sick Children (SickKids, Toronto, Canada). One of the coauthors (MK) worked in both centers during her pediatric nephrology training and noticed that these centers used similar clinical care and perioperative protocols. The method of stenting the ureter postoperatively was different, however, with the splint used at Erasmus MC and the JJ catheter at SickKids.

We aimed at including at least 50 consecutive, most recently transplanted children at each center in whom ureteral stenting was applied. Children were eligible if less than 18 years old at time of transplantation and if having received a first or second $A B O$ compatible graft from a deceased or LD. The following exclusion criteria were applied: follow-up at either center less than 3 months after transplantation, or transplant failure within the first week. The included children at Erasmus MC formed the splint group; those at SickKids the JJ catheter group. The protocol was reviewed, and informed consent was waived by both the Medical Ethical Review Board (Erasmus MC), and the Research Ethics Board (SickKids).

\section{2 | Treatment protocols}

In both centers, kidney grafts were predominantly positioned in the iliac fossa, or if recipients were too small, intra-abdominally. Vascular anastomoses were performed by a transplantation surgeon and the ureteroneocystostomy by a pediatric urologist. In both centers, the extravesical re-implantation technique (non-refluxing anastomosis) was used. At SickKids, a ureteroureterostomy was performed if the donor ureter was short or poorly vascularized or if the recipient had a very small bladder. A JJ catheter was placed from the bladder through the newly implanted ureter into the pelvis. At Erasmus MC not a JJ but a splint was positioned with the tip located in the pelvis, traversing the ureter and bladder, and opening through the abdominal wall (Figure 1). By protocol, the splint was removed during hospitalization 8 days after transplantation and the JJ catheter was removed 6 weeks after transplantation in day care setting. At SickKids, the bladder was drained with a transurethral catheter for 1 week, at Erasmus MC with a transurethral catheter for 1 day and a suprapubic catheter until at least 1 day after removal of the splint.
(A)

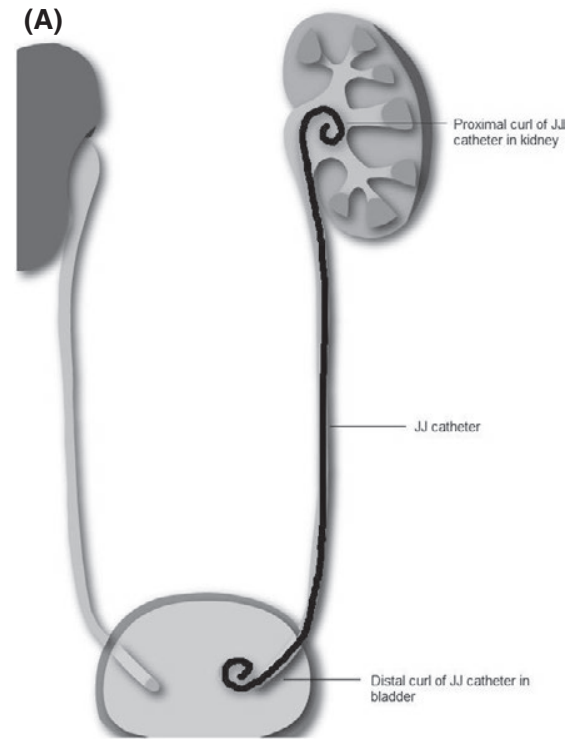

(B)

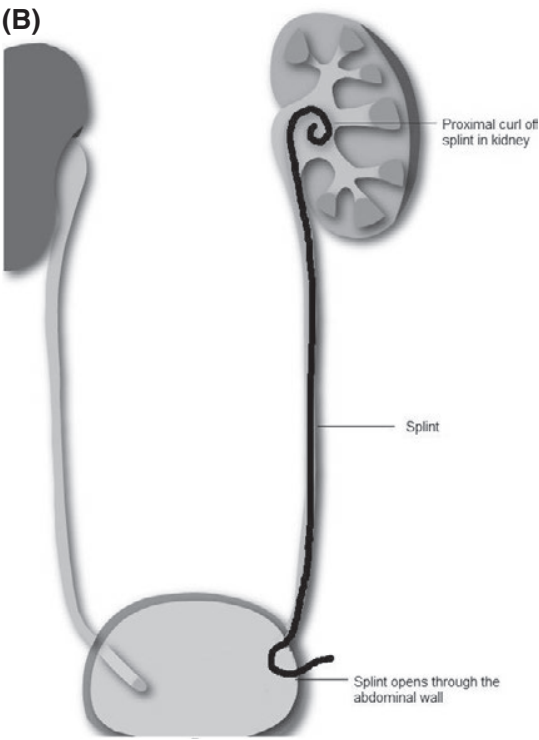

FIGURE 1 Position of JJ catheter (A) and splint (B). The $J J$ catheter has one curled tip in the pelvis and runs through the newly implanted ureter, with the curled tip at the other end located in the bladder. The splint is placed with the tip located in the pelvis, traverses the ureter and bladder, and opens through the abdominal wall 
Basiliximab was used as standard induction of immunosuppressive therapy in both centers, except that at SickKids children who received a second kidney transplant or were highly sensitized received ATG. For all children, maintenance immunosuppressive therapy consisted of mycophenolate mofetil in combination with tacrolimus or cyclosporine, with or without prednisolone. Cotrimoxazole was routinely given as antibiotic prophylaxis for 3 months at both centers. Children at SickKids in addition received antifungal prophylaxis. In the first week after transplantation, all children had at least one ultrasound study of the kidney graft. During the first 2 weeks, urine cultures were performed at least twice a week in both centers and thereafter on indication.

\section{3 | Data collection}

The following data were obtained from an electronic patient record: baseline characteristics (age, gender, primary renal disease, recent dialysis modality, last serum creatinine level before transplantation, occurrence of vesicoureteral reflux or recurrent UTIs, and history of urologic interventions), transplant characteristics (donor source, details of graft), surgery data date of surgery, site of graft placement, and ureter implantation method, immunosuppressive medication and follow-up outcomes (complications, UTIs, acute rejection episodes, BK PCR in blood, results of renal scans, ultrasounds, and voiding cystourethrogram).

\subsection{Outcome measures and definitions}

Primary outcome measures were the number of urologic reinterventions for severe ureteric obstruction, including replacement of an obstructed stent, a PCN or re-implantation of the ureter, and the incidence and timing of UTIs during the first 3 months posttransplant. Secondary outcomes were urinary leakage and fluid collections (defined as diagnosed on ultrasound and treated with intervention for drainage). A UTI was defined as a positive culture $>10^{5}$ colony-forming units on midstream urine or $\geq 10^{3}-10^{4}$ colony-forming units per liter on a urinary catheter specimen in combination with a therapeutic course of antibiotics. A recurrent UTI was defined either after a negative urine culture, or one re-occurring at least 2 weeks after interruption of antibiotic treatment.

\section{5 | Statistical analysis}

Statistical analysis was performed using Statistical Package for the Social Sciences version 21 (SPSS, Chicago, IL, USA). Results were expressed as median with IQR for continuous variables or as number with percentage value (\%) for categorical variables. For univariate overall comparisons, the Mann-Whitney $U$ test or the Pearson's chi-squared test was used as appropriate. Survival analysis for the urological interventions and occurrence of a first UTI was performed using the Kaplan-Meier technique and log rank statistics. In all analyses, $P$-value $<.05$ was considered the limit of significance.
TABLE 1 Demographic and clinical characteristics

\begin{tabular}{|c|c|c|}
\hline & $\begin{array}{l}\text { Splint } \\
(N=61)\end{array}$ & $\begin{array}{l}\mathrm{JJ} \text { catheter } \\
(\mathrm{N}=50)\end{array}$ \\
\hline \multicolumn{3}{|l|}{ Age at transplant } \\
\hline Median (IQR) & $11.9(5.9-15.5)$ & $13.7(6.6-16.2)$ \\
\hline$<5$ years of age & $13(21.3 \%)$ & $8(16.0 \%)$ \\
\hline \multicolumn{3}{|l|}{ Gender } \\
\hline Male & 33 (54.1\%) & $30(60.0 \%)$ \\
\hline \multicolumn{3}{|l|}{ Primary renal diagnosis } \\
\hline Obstructive uropathy & $15(24.6 \%)$ & 5 (10.0\%) \\
\hline Reflux nephropathy & $3(4.9 \%)$ & $5(10.0 \%)$ \\
\hline Other CAKUT & $10(16.4 \%)$ & $12(24.0 \%)$ \\
\hline Other & $33(54.1 \%)$ & $28(56.0 \%)$ \\
\hline History of urological interventions & $N=15(24.6 \%)$ & $N=16(32.0 \%)$ \\
\hline Vesicostoma or ureterostomy & $3(4.9 \%)$ & 7 (14.0\%) \\
\hline Bladder augmentation & $1(1.6 \%)$ & $4(8.0 \%)$ \\
\hline Appendicovesicostomy & $1(1.6 \%)$ & 4 (8.0\%) \\
\hline Nephrectomy & $10(16.4 \%)$ & 8 (16.0\%) \\
\hline $\mathrm{CIC}$ at time of transplantation & $5(8.2 \%)$ & $8(16.0 \%)$ \\
\hline Recurrent UTIs & 24 (39.0\%) & $12(24.0 \%)$ \\
\hline \multicolumn{3}{|l|}{ VUR } \\
\hline None & $39(63.9 \%)$ & $38(76.0 \%)$ \\
\hline Grade 1 & $3(4.9 \%)$ & $2(4.0 \%)$ \\
\hline Grade 2 & $2(3.3 \%)$ & $1(2.0 \%)$ \\
\hline Grade 3 & $3(4.9 \%)$ & 1 (2.0\%) \\
\hline Grade 4 & $2(3.3 \%)$ & 4 (8.0\%) \\
\hline Grade 5 & 10 (16.4\%) & $3(6.0 \%)$ \\
\hline Preemptive transplantation & 19 (31.1\%) & $12(24.0 \%)$ \\
\hline \multicolumn{3}{|l|}{$\begin{array}{l}\text { Immunosuppressive therapy } \\
\text { Induction therapy** }\end{array}$} \\
\hline ATG & 0 & 25 (50.0\%) \\
\hline Basiliximab & 60 (98.4\%) & 25 (50.0\%) \\
\hline None & $1(1.6 \%)$ & 0 \\
\hline \multicolumn{3}{|l|}{ Maintenance therapy** } \\
\hline Tacrolimus + MMF & 25 (41.0\%) & $6(12 \%)$ \\
\hline $\begin{array}{l}\text { Tacrolimus + MMF + pred- } \\
\text { nisone }\end{array}$ & $4(6.6 \%)$ & $44(88 \%)$ \\
\hline $\mathrm{CsA}+\mathrm{MMF}$ & $6(9.8 \%)$ & 0 \\
\hline CsA + MMF + prednisone & $26(42.6 \%)$ & 0 \\
\hline \multicolumn{3}{|l|}{ Donor origin* } \\
\hline LD & 34 (55.7\%) & $18(35.0 \%)$ \\
\hline \multicolumn{3}{|l|}{ Position kidney graft } \\
\hline Intra-abdominal & $0(0.0 \%)$ & 5 (10.0\%) \\
\hline \multicolumn{3}{|l|}{ Ureter implantation** } \\
\hline Extravesical & $61(100 \%)$ & 40 (80.0\%) \\
\hline Ureteroureterostomy & & $10(20.0 \%)$ \\
\hline
\end{tabular}

Other CAKUT includes: dysplasia without urological abnormalities, ciliopathy; Sober, pyelocutaneostomy.

*Significant $P$-value $<.05$.

** Significant $P$-value $<.001$. 


\begin{tabular}{|c|c|c|c|}
\hline & $\begin{array}{l}\text { Splint } \\
(\mathrm{N}=61)\end{array}$ & $\begin{array}{l}J J \text { catheter } \\
(\mathrm{N}=50)\end{array}$ & $P$-value \\
\hline $\begin{array}{l}\text { Number of children with at least } 1 \text { urologic } \\
\text { intervention post-transplant }\end{array}$ & $7(11.5 \%)$ & $2(4.0 \%)$ & .15 \\
\hline $\mathrm{PCN}$ & 3 & 1 & \\
\hline PCN converted to $\mathrm{JJ}$ catheter & 2 & & \\
\hline (Renewal of) JJ catheter & 4 & 1 & \\
\hline J catheter + SPC & 2 & & \\
\hline $\begin{array}{l}\text { Number of children with at least } 1 \text { UTI within } \\
3 \text { months post-transplant }\end{array}$ & $19(31.1 \%)$ & $25(50.0 \%)$ & .04 \\
\hline Number of UTIs & 27 & 57 & .02 \\
\hline Number of UTIs during presence of stent & 9 & 35 & $<.001$ \\
\hline $\begin{array}{l}\text { Number of children with at least } 1 \\
\text { complication }\end{array}$ & $23(37.7 \%)$ & $25(50.0 \%)$ & .20 \\
\hline
\end{tabular}

TABLE 2 Urological interventions and UTIS

\section{3 | RESULTS}

At Erasmus MC, the cohort of transplant recipients between 2006 and April 2014 consisted of 66 children, of whom 5 did not meet the inclusion criteria. Consequently, the splint group consisted of 61 children. At SickKids, 22 of the most recent 72 eligible children were excluded, mainly because follow-up at SickKids was less than 3 months due to follow-up in hospitals more close to the home address of the patients. Thus, 50 children transplanted between 2010 and 2014 formed the JJ catheter group. The baseline characteristics of both groups are shown in Table 1. The groups were comparable, except for donor source and induction therapy protocol. One child of the $\mathrm{JJ}$ catheter group did not receive the antibiotic prophylaxis for the full 3 months because of a low leukocyte count. In the splint group, the stent was removed at a median of $9^{8-12}$ days and in the $\mathrm{J}$ catheter group at a median of 42 (36-50) days ( $P$-value <.001).

\section{1 | Urological complications/interventions (Table 2; Figure 2)}

Within the follow-up period, 7 (11.5\%) children in the splint group needed 9 urological re-interventions. Three needed a PCN, which in 2 cases were converted to a JJ catheter. In one of these 3 children, the PCN had already been inserted 6 days post-transplant due to obstruction of the splint; the other 2 children received a PCN 9 and 17 days, respectively, after removal of the splint. Two children received a JJ catheter 50 and 52 days, respectively, after removal of the splint. One of these procedures had to be interrupted due to surgical problems, after which the serum creatinine level improved spontaneously. Two other children received a JJ catheter after 31 and 36 days, respectively, together with a SPC for drainage of the bladder. In the JJ catheter group, 2 children (4.0\%) ( $P$-value .15 compared to splint group) received a urological re-intervention: renewal of an obstructed $\mathrm{J} J$ catheter after 15 days and insertion of a PCN 28 days after removal of the $\mathrm{J} J$ catheter. Overall, there was no difference in urological complications in children $<5$ years old and children $>5$ years old ( $P$-value .79$)$.

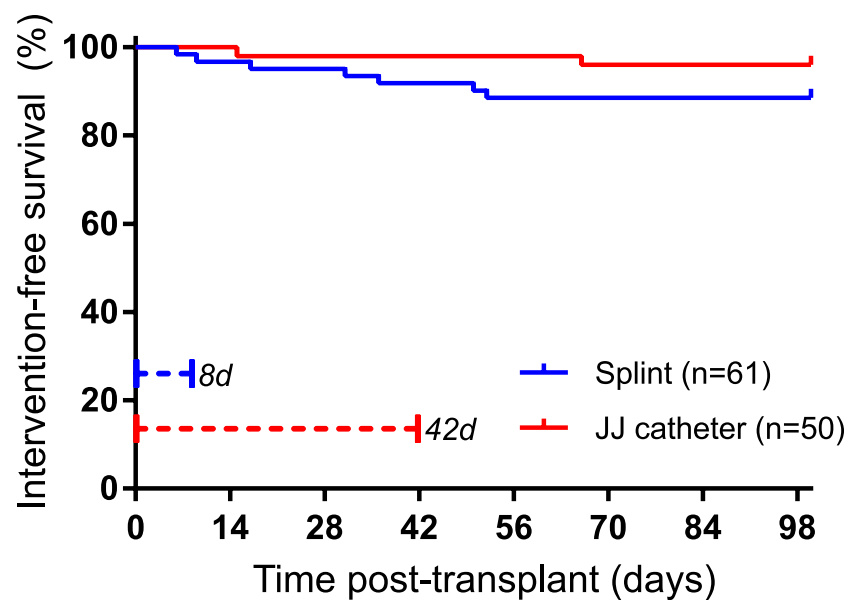

FIGURE 2 Time to the first urologic intervention during the first 3 months after kidney transplantation. The curves indicate the timing of urologic interventions in the time post-transplant. The solid line represents the splint group and the dotted line the JJ catheter group. The splint remained in situ for a median time of 8 days and the $\mathrm{JJ}$ catheter for 42 days

\section{2 | Urinary tract infections (Table 2; Figure 3)}

Figure 3 shows the incidence of a first UTI per child during the first 3 months post-transplant. In the splint group, 19 (31.1\%) children developed a total of 27 UTI episodes: one in 13 children, two in 5 children, and four in 1 child. Nine of these occurred with the splint in situ. In the JJ catheter group, 25 children (50.0\%, $P$-value .04) had a total of 57 UTI episodes ( $P$-value .02 compared to the splint group), of which 35 with the $\mathrm{J} J$ catheter in situ $(P<.001)$. Eight children developed 1 , seven children 2 , seven children 3 , one child 4 , and two children 5 episodes. There was no difference in UTIs in children $<5$ years old and children $>5$ years old ( $P$-value .41$)$. No correlation between immunosuppression and UTI was seen with univariate analysis, and adjustment for immunosuppression did not change results between way of stenting and UTI's. In total 23 (37.7\%), children of the splint group had at least one of the above-mentioned complications versus 25 (50.0\%) children of the JJ catheter group (P-value .20). 


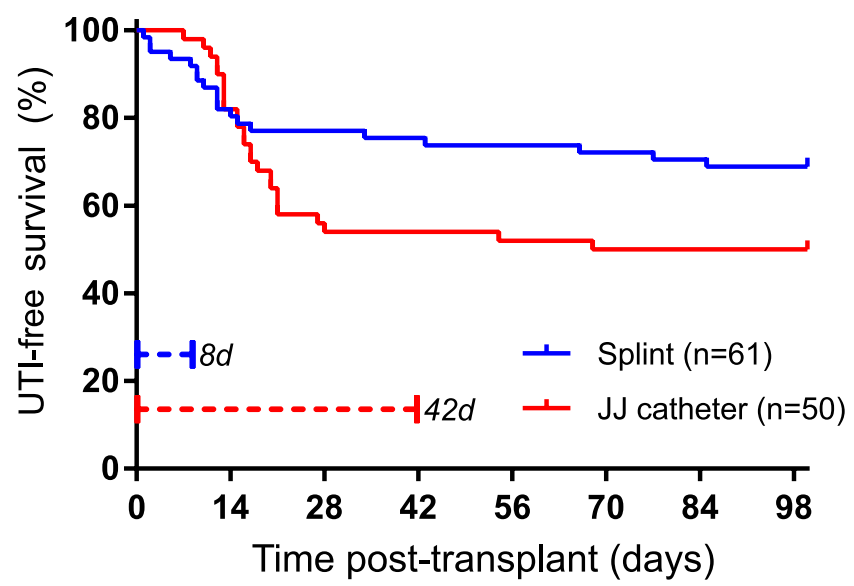

FIGURE 3 Time to the first UTI per child during the first 3 months after kidney transplantation. The curves indicate the timing of the first UTI per child in the time post-transplant. The splint remained in situ for a median time of 8 days and the $\mathrm{JJ}$ catheter for 42 days

\section{3 | Other complications}

Urinary leakage occurred in 2 children in each group ( $P$-value .84). In one case in the splint group, urine was drained by the wound drain; in the other case, leakage of the ureter-bladder passage was seen on the voiding cystourethrogram. Both leakages resolved spontaneously. The two cases in the $\mathrm{J}$ catheter group concerned urinary leakage at the ureteroureterostomy. In one case, the stent was replaced, and in the other case, the wound was drained. Perinephric fluid collections requiring drainage were found only in 6 children in the $\mathrm{J}$ catheter group. At biochemical analysis, these appeared to be lymphoceles. Three of these six children received a laparoscopic intervention, and three were drained externally. In total, 8 children (16\%) in the JJ catheter group had a positive BK PCR, and in the splint group, BK PCR was not routinely monitored.

\section{4 | DISCUSSION}

In this study, comparison of two methods of ureteral stenting after pediatric renal transplantation showed a trend of a higher need of reintervention with the use of splints. On the other hand, the use of JJ catheters was significantly associated with a higher incidence of UTIs within the first 3 months post-transplant.

These findings, obtained in a large number of children, highlight that both methods of stenting have limitations. Few published studies have compared complication rates of different ureteral stents. In the only pediatric study, ureteric obstruction occurred in one-third of 39 children with an indwelling splint for a median of 5 days, requiring insertion of a PCN or JJ catheter in four cases. ${ }^{7}$ After a protocol change mandating the use of a JJ catheter for up to 8 weeks, only 1 of 16 children required PCN for ureteric obstruction. ${ }^{7}$ In contrast, in adults, removal of a J catheter as early as after 7 or 8 days was not associated with a higher rate of ureteral obstruction or urinary leakage compared to removal after 15 or 28 days. ${ }^{22,23}$ Recently, a study in adult patients showed significantly lower incidence of urological complications with a JJ catheter for 6 weeks compared to an external SP stent for 5 days and no difference in UTIs. ${ }^{24}$

Bacterial UTIs form the most common infectious complication in the first weeks after renal transplantation in children, with a higher incidence than in adults. Although most UTIs can be treated well with antibiotics, they threaten the graft function, potentially leading to chronic injury. ${ }^{25}$ The use of any ureteral stent introduces the risk of bacteriuria due to colonization of the foreign material and is consequently associated with a risk of UTI. This association has been often recognized and reported, although not all studies confirm this. ${ }^{8-11,14-18,20,26}$ Longer duration of stenting may therefore induce a higher risk of UTIs. In adults, removal of the JJ catheter after 7 or 8 days was associated with a lower incidence of UTIs compared to removal after 15 or 28 days. ${ }^{22,23}$ Our study confirms this relation with a higher rate of, both primary and recurrent, UTIs in children with the longer indwelling $J J$ catheters than in children with splints.

Our results are confirmed by a recent a randomized controlled trial published by Patel et al. aiming to determine the optimal dwell time of a stent. All patients, of which $17 \%$ were children, received a JJ catheter which was removed early on day 5 or late at 6 weeks. In the early stent removal group, the $\mathrm{J}$ catheter was attached to the urethral catheter using the string of the stent, thus enabling to easily remove the $\mathrm{JJ}$ catheter. At 6 weeks, the JJ catheter was removed by cystoscopy. In the late removal group, stent-related complications, especially UTIs, were significantly more frequent. These indicate that early removal reduces significantly stent-related complications. ${ }^{27}$ In several studies, stenting is identified as an independent risk factor of another infectious complication, that is BK virus nephropathy. ${ }^{28,29}$ In all studies reporting this association, stenting was performed with an indwelling $\mathrm{JJ}$ catheter. Unfortunately, a comparison of the incidence of BK virus nephropathy between the splint and JJ catheter was not possible with our available clinical data.

Consequently, irrespective of the method applied, finding the optimal duration of stenting would ensure the full benefits of stenting while minimizing the disadvantages. A minimum duration is crucial to avoid stricture of the ureterovesical anastomosis; on the other hand, the longer the stent remains in situ, the higher the risk of infection. Our study is not conclusive on this optimal dwell time. More evidence could be obtained from a larger, prospective randomized controlled trial in the pediatric population comparing the use of a JJ catheter and splint. Stent-related side effects such as internal obstruction, stent breakage, stent migration, and bleeding are considered reasons to discourage routine ureteric stent utilization. ${ }^{15}$ No such complications were documented in the 111 children included in our study.

Compared to splints, JJ catheters have some drawbacks. First, some case reports describe indwelling $\mathrm{J}$ catheters left in situ, causing considerable morbidity due to infection, hematuria, encrustations, or migration. ${ }^{30}$ Second, the $\mathrm{J}$ catheter must be removed through another invasive cystoscopic procedure, requiring general anesthesia, whereas an external splint is easily pulled out. Every invasive procedure is a potentially stressful experience for a child and should be avoided as 
much as possible. Third, with the use of a $\mathrm{J}$ catheter it is not possible to separately analyze the urine from the transplanted kidney. This is particularly disadvantageous with diseases such as focal segmental glomerulosclerosis with the risk of early recurrence of proteinuria, and polyuria of the native kidneys with the risk of dehydration of the graft.

Unexpectedly, six children in the JJ catheter group developed a lymphocele, but none in the splint group. We cannot think of a causal relation between the use of a ureteral stent and the development of a lymphocele and therefore suggest this is an occasional finding; in addition, the low incidence of this phenomenon did not justify building statistical models for further analysis.

A major strength of the study is the relatively large, contemporary cohort of children treated in two different centers with a similar clinical protocol. Still, some limitations need to be addressed. First, the treatment protocols in the two participating centers differed in details. For example, more children in the JJ catheter group received ATG by protocol whereas children in the splint group only received basiliximab as induction therapy. We do not think that this difference will have affected the results in terms of urological complications. Second, the study was retrospective in nature, which implies that we could not identify, for example, other factors contributing to the development of the lymphoceles.

In conclusion, the use of a JJ catheter in children was associated with a higher incidence of UTIs than the use of a splint within the first 3 months post-transplant. The latter method, however, tended to be associated with more re-interventions. Therefore, neither of these two urinary drainage methods seems to be ideal, and further modification of either method, for example, in terms insertion duration, is needed to find the best way to stent the ureter.

\section{AUTHORS' CONTRIBUTIONS}

Anuradha S. ter Haar: Data Collection, drafting article, data analysis/ interpretation, and statistics; Rulan S. Parekh, Ralph W. J. Leunissen, Mandy G. Keijzer-Veen: Concept/design and critical revision of article; Joop van den Hoek, Armando J. Lorenzo, and Diane Hebert: Critical revision of article; Karlien Cransberg: Concept/design, drafting article, data analysis/interpretation, statistics, and critical revision of article.

\section{ORCID}

Anuradha S. ter Haar (iD http://orcid.org/0000-0002-0635-3566

\section{REFERENCES}

1. Cecka M. Clinical outcome of renal transplantation. Factors influencing patient and graft survival. Surg Clin North Am. 1998;78:133-148.

2. Kari JA, Romagnoli J, Duffy P, Fernando ON, Rees L, Trompeter RS. Renal transplantation in children under 5 years of age. Pediatr Nephrol. 1999;13:730-736

3. Alberts VP, Minnee RC, Bemelman FJ, van Donselaar-van der Pant KA, Laguna Pes P, Idu MM. Ureteral reconstruction after renal transplantation: clinical outcome and risk factors. Urol Int. 2012;88:333-337.
4. Irtan S, Maisin A, Baudouin V, et al. Renal transplantation in children: critical analysis of age related surgical complications. Pediatr Transplant. 2010;14:512-519.

5. Martino P, Impedovo SV, Palazzo S, et al. Ureteral strictures after kidney transplantation: risk factors. Arch Ital Urol Androl. 2012;84:287-290.

6. Almeida F, Branco F, Cavadas V, et al. Urological complications after 134 pediatric kidney transplants: a single-center study. Transplant Proc. 2013;45:1096-1098.

7. Simpson CM, Sterne JA, Walker RG, Francis DM, Robertson AJ, Jones $\mathrm{CL}$. Stent-related ureteric obstruction in paediatric renal transplantation. Pediatr Nephrol. 2006;21:79-85.

8. Tavakoli A, Surange RS, Pearson RC, Parrott NR, Augustine T, Riad HN Impact of stents on urological complications and health care expenditure in renal transplant recipients: results of a prospective, randomized clinical trial. J Urol. 2007;177:2260-2264; discussion 4.

9. Harza M, Baston C, Preda A, et al. Impact of ureteral stenting on urological complications after kidney transplantation surgery: a singlecenter experience. Transplant Proc. 2014;46:3459-3462.

10. Akoh JA, Rana T. Effect of ureteric stents on urological infection and graft function following renal transplantation. World J Transplant. 2013;3:1-6.

11. Dharnidharka VR, Araya CE, Wadsworth CS, McKinney MC, Howard RJ. Assessing the value of ureteral stent placement in pediatric kidney transplant recipients. Transplantation. 2008;85:986-991.

12. Randhawa $\mathrm{P}$, Brennan DC. BK virus infection in transplant recipients: an overview and update. Am J Transplant. 2006;6:2000-2005.

13. Mangus RS, Haag BW. Stented versus nonstented extravesical ureteroneocystostomy in renal transplantation: a metaanalysis. Am J Transplant. 2004;4:1889-1896.

14. Wilson $\mathrm{CH}$, Rix DA, Manas DM. Routine intraoperative ureteric stenting for kidney transplant recipients. Cochrane Database Syst Rev. 2013;17:CD004925.

15. Sansalone CV, Maione G, Aseni P, et al. Advantages of short-time ureteric stenting for prevention of urological complications in kidney transplantation: an 18-year experience. Transplant Proc. 2005;37:2511-2515.

16. Georgiev P, Boni C, Dahm F, et al. Routine stenting reduces urologic complications as compared with stenting "on demand" in adult kidney transplantation. Urology. 2007;70:893-897.

17. Ordon M, Ghiculete D, Stewart R, Pace KT, Honey RJ. The role of prophylactic versus selective ureteric stenting in kidney transplant patients: a retrospective review. Prog Transplant. 2014;24:322-327.

18. Minnee RC, Bemelman FJ, Laguna Pes PP, ten Berge IJ, Legemate DA, Idu MM. Effectiveness of a 5-day external stenting protocol on urological complications after renal transplantation. World J Surg. 2009;33:2722-2726.

19. Gedroyc WM, Koffman G, Saunders AJ. Ureteric obstruction in stented renal transplants. Br J Urol. 1988;62:123-126.

20. Bergmeijer JH, Nijman R, Kalkman E, Nauta J, Wolff ED, Molenaar JC. Stenting of the ureterovesical anastomosis in pediatric renal transplantation. Transpl Int. 1990;3:146-148.

21. French CG, Acott PD, Crocker JF, Bitter-Suermann H, Lawen JG. Extravesical ureteroneocystostomy with and without internalized ureteric stents in pediatric renal transplantation. Pediatr Transplant. 2001;5:21-26.

22. Indu KN, Lakshminarayana $\mathrm{G}$, Anil M, et al. Is early removal of prophylactic ureteric stents beneficial in live donor renal transplantation? Indian J Nephrol. 2012;22:275-279.

23. Parapiboon W, Ingsathit A, Disthabanchong S, et al. Impact of early ureteric stent removal and cost-benefit analysis in kidney transplant recipients: results of a randomized controlled study. Transplant Proc. 2012;44:737-739

24. Fockens MM, Alberts VP, Bemelman FJ, Laguna Pes MP, Idu MM. Internal or external stenting of the ureterovesical anastomosis in renal transplantation. Urol Int. 2016;96:152-156. 
25. Silva A, Rodig N, Passerotti CP, et al. Risk factors for urinary tract infection after renal transplantation and its impact on graft function in children and young adults. J Urol. 2010;184:1462-1467.

26. Mathe Z, Treckmann JW, Heuer M, et al. Stented ureterovesical anastomosis in renal transplantation: does it influence the rate of urinary tract infections? Eur J Med Res. 2010;15:297-302.

27. Patel P, Rebollo-Mesa I, Ryan E, et al. Prophylactic ureteric stents in renal transplant recipients: a multicenter randomized controlled trial of early versus late removal. Am J Transplant. 2017;17:2129-2138.

28. Maliakkal JG, Brennan DC, Goss C, et al. Ureteral stent placement and immediate graft function are associated with increased risk of BK viremia in the first year after kidney transplantation. Transpl Int. 2017;30:153-161.

29. Hashim F, Rehman S, Gregg JA, Dharnidharka VR. Ureteral stent placement increases the risk for developing BK Viremia after kidney transplantation. J Transplant. 2014;2014:459747.
30. Bardapure M, Sharma A, Hammad A. Forgotten ureteric stents in renal transplant recipients: three case reports. Saudi J Kidney Dis Transpl. 2014;25:109-112.

How to cite this article: ter Haar AS, Parekh RS, Leunissen RWJ, et al. How to stent the ureter after kidney transplantation in children?-A comparison of two methods of urinary drainage. Pediatr Transplant. 2018;22:e13065. https://doi.org/10.1111/ petr.13065 